\title{
EDITORIAL
}

\section{Heads of OR}

It gives me particular pleasure to introduce this edition of OR Insight, which has been sponsored by the $O R$ Society's Heads of OR Committee. During John Ranyard's tenure of the office of OR Society President, one of his successful initiatives was to implement the recommendations of the Commission on the Future Practice of OR to set up a Heads of OR Group. This came into being in early 1987, and has since become a very active contributor to the affairs of our Society. The Group has now become a Committee of Council, and very high on our agenda are the two aims of publicising the best of $O R$ practice and improving client awareness and receptiveness. We felt that there could be no better way of supporting those aims than by sponsoring one of the future issues of OR Insight.

So there we are, and here it is! We are particularly grateful to Stephen Ward and his colleagues on the Publications Committee for entrusting us with this edition. I hope that you will all agree that this trust was not misplaced and that the quality and relevance of the articles will add to the body of literature on "the best practice of OR". Thanks too are due to Tony Taylor of Unipart Group. He has been a longstanding and active member of HORC, and undertook the difficult role of masterminding this edition. I believe we all now appreciate what a difficult and time-consuming business it is to be responsible for publishing a journal like $O R$ Insight. I would like to take this opportunity to thank Stephen for his excellent efforts and to encourage my fellow-practitioners to keep those articles coming! I hereby affirm that my group will produce at least one paper before the end of 1991 . Unless we make this sort of commitment, the good practice of OR will not be shared and publicised as it should.

The National Events Committee have asked HORC to consider the possibility of organizing and mounting an Event on the subject of "OR in Recession". This would seem an appropriate time to address such a subject. Firstly, what contribution can OR bring to help the successful management of our organizations during recessionary times? Secondly, how do we manage a recession in the demand for OR services? I believe the NEC were thinking of the first interpretation, and the articles published herein give plentiful evidence of our profession's ability to unravel and make sense of complex strategic issues which directly affect the "bottom line". I have personally been involved in an evaluation of the contribution OR makes in my own company, so that my OR group does not go into recession. Fortunately, I had done some image-research among my clients, who all gave a "thumbs up", and we were profitable in 1990. Thus I had a good basis from which to argue. Stephen Ward in his Editorial in the previous Insight touched on complacency being a contributory factor in the downfall of some OR groups, and despite having managed to keep mine in being I have realized that we have been guilty of this to some extent. To enable ourselves to see more clearly, and to encourage "possibility thinking", we are putting into place some of the ideas of Tom Peters as revealed in his book Thriving on Chaos. In the book, Peters puts forward prescriptions for a world turned upside-down. It is all about creating total customer responsiveness, pursuing fast-paced innovation, achieving flexibility by empowering people and learning to love change. This is certainly the most thoughtprovoking book I have read, and certainly challenges complacency! The lesson I am learning is that successful OR depends far more on the way in which it is managed and applied than on its technical content (though this too must be there and of appropriate quality). The success of individual OR groups depends to a large extent on the calibre of the team members and the way in which they are motivated and led. HORC obviously recognise this truism, and we are taking an initiative to improve understanding of staff development and recruitment issues by running an Event that addresses the identification of good OR staff, getting the best out of them and developing them. This will take place on 6th7th June, and I hope many senior practitioners will be able to join us so that we can benefit from shared experience.

RICHARD NICHOLLS

\section{For the interested reader}

Peters, Tom (1987): Thriving on Chaos: Handbook for a Management Revolution, Alfred A. Knopf (in UK Pan Books).

RICHARD NICHOLLS heads the Cadbury-Schweppes OR Group, which is based within the IT subsidiary ITnet Ltd. He has held senior positions in industrial engineering and manufacturing before transferring into OR. He is a Council member of the OR Society and is the 1991 Chairman of HORC. 